\title{
Growing Pains: How Risk Perception and Risk Communication Research Can Help to Manage the Challenges of Global Population Growth
}

Running head: Risk and Global Population Growth

Ian G.J. Dawson ${ }^{1}$, and Johnnie E.V. Johnson ${ }^{1}$

${ }^{1}$ Centre for Risk Research, University of Southampton, Southampton, SO17 1BJ, UK.

*Correspondence should be addressed to Ian G.J. Dawson, Centre for Risk Research, School of Management, University of Southampton, SO17 1BJ, UK. (e-mail:

I.G.Dawson@Soton.ac.uk).

Acknowledgments: We would like to thank Professor Michael Siegrist and the anonymous reviewers for their helpful and insightful comments regarding an earlier draft of this paper. 


\begin{abstract}
In 2011 the global human population reached seven billion and medium variant projections indicate that it will exceed nine billion before 2045. Theoretical and empirical perspectives suggest that this growth could lead to an increase in the likelihood of adverse events (e.g., food shortages, climate change, etc.) and/or the severity of adverse events (e.g., famines, natural disasters, etc.). Several scholars have posited that the size to which the global population grows and the extent to which this growth increases the likelihood of adverse outcomes will largely be shaped by individuals' decisions (in households, organizations, Governments, etc.). In light of the strong relationship between perceived risk and decision behaviors, it is surprising that there remains a dearth of empirical research that specifically examines the perceived risks of population growth and how these perceptions might influence related decisions. In an attempt to motivate this important strand of research, this paper examines the major risks that may be exacerbated by global population growth and draws upon empirical work concerning the perception and communication of risk to identify potential directions for future research. The paper also considers how individuals might perceive both the risks and benefits of population growth and be helped to better understand and address the related issues. The answers to these questions could help humanity better manage the emerging consequences of its continuing success in increasing infant survival and adult longevity.
\end{abstract}

\title{
KEYWORDS
}

Decision making, population growth, risk perception, risk communication 


\section{INTRODUCTION}

The global human population reached approximately 200 million for the first time in $1 \mathrm{AD}$, but did not reach one billion until around 1850 . Since then it has increased rapidly, reaching two, four, six and seven billion in 1927, 1974, 1999, and 2011 respectively (see Figure 1). ${ }^{[1]}$ Medium fertility variant projections indicate that the population will increase by approximately 70 million every year between now and 2045, reaching between nine and ten billion by $2050 \cdot{ }^{[2,3]}$ The rapid changes associated with this growth and the absolute level of the global population presents unprecedented challenges for humanity and the natural environment. ${ }^{[4,5]}$ Furthermore, human beings have no prior experience of coping with such population levels. ${ }^{[6]}$

\section{[Insert Figure 1 about here]}

Since the industrial revolution began in the 1700s, general living standards have improved, helping to increase infant survival rates and adult longevity. ${ }^{[7]}$ Whilst such achievements are typically regarded as affirmations of human ingenuity, ${ }^{[5]}$ the related and continuing population boom has, more recently, raised concerns amongst academics about (a) the earth's capacity to provide sufficient resources to meet the demands of the existing and projected populations (b) the impact of a large population on the supporting natural environment and (c) the consequences of these impacts for living conditions. ${ }^{[8-10]}$ These concerns are increasingly being brought to public consciousness by the growing coverage of population growth in the media, non-fiction books and dedicated websites. ${ }^{[1-16]}$

Whilst global population growth has received considerable attention in academic disciplines such as geography, humanities, and economics, it has received less attention from the behavioral sciences and, more specifically, from those researching risk perception, risk communication, and behavioral decision making. This is surprising in light of (a) the large body of evidence that shows risk perceptions can have a substantial influence on important decisions and behaviors, ${ }^{[17-19]}$ and (b) the assertions by several scholars and organizations that, as the population continues to grow, people's decisions will have substantial effects on the demographic, political, economic and ecological shape of humanity during the $21^{\text {st }}$ century ${ }^{[6,10,13,14,20-23]}$. Hence, this paper aims to motivate a new strand of empirical research that specifically examines the perceived risks of population growth and how these perceptions might influence related decisions. We argue that this research would help 
establish a coherent and rigorous scientific knowledge base concerning the perceived risks of global population growth, how these perceptions could be influenced by risk communications, how risk perceptions might shape decision making, and how these decisions might shape population growth and the related challenges.

We initially present an overview of some of the major risks that the academic literature indicates may result from population growth during the forthcoming decades and, in doing so, implicitly illustrate why individuals (e.g., laypersons, policy makers, experts, etc.) might perceive global population growth as a major independent or contributory risk factor underlying the challenges faced by humanity. We then consider the importance of understanding these perceived risks, how these perceptions might affect decision behaviors, and how risk communications may play a role in shaping these perceptions and behaviors. Based on these insights, we identify directions for future risk perception and communication research that we believe could be utilized to help manage the evolving consequences of humanity's continuing success in increasing infant survival rates and adult longevity.

\section{POPULATION GROWTH AND RISK}

Population growth can interact with other natural and socio-technical factors to increase many of the risks that people face. ${ }^{[6,24,25]}$ For example, the adverse, multiplicative effect of the interaction between population size, technology and socio-economic conditions are illustrated by the IPAT model (Impact $[\mathrm{I}]=$ Population $[\mathrm{P}] \times$ Affluence $[\mathrm{A}] \mathrm{x}$ Technology $[\mathrm{T}]$ ) (see Figure 2) and other more advanced versions of this model, such as ImPACT and STIRPA. ${ }^{[26-28]}$ IPAT analysis indicates that by 2050, despite large advances in technological efficiencies, the interaction of population growth and increased consumption will lead to an environment impact between 2.5 and 5 times the level observed in $1987\left({ }^{[29]}\right.$ but also see ${ }^{[30]}$ ). Whilst the simplicity of these models has been criticized (see ${ }^{[28]}$ ), they illustrate how population size can interact with other factors to produce an adverse synergistic effect. Consequently, we now consider how the growing global population might interact with natural, technological and social processes to increase the likelihood and/or severity of some of the major adverse outcomes that may ensue.

[Insert Figure 2 about here] 


\subsection{Potential Consequences of Future Population Growth}

\subsubsection{Resource Shortages}

Industrialization and technological advancements have enabled the expanding human population to achieve a per capita increase in consumption of natural resources. ${ }^{[6]}$ For example, since 1940 the Earth's population has approximately doubled, but it is estimated that consumption has more than tripled. ${ }^{[31]}$ Concerns arise because it is uncertain to what extent the pressures created by increasing consumption can be met in a world populated by over nine billion people ${ }^{[32,33]}$ and whether these consumption demands can be met in an environmentally and economically sustainable way. ${ }^{[34,35]}$ Furthermore, the extent to which global resources are distributed in an equitable manner could influence the magnitude of the consequences of population growth for many societies. ${ }^{[13]}$ For example, Bourlag asserts that if, in the forthcoming decades, the existing inequitable distribution of resources between nations continues poverty levels in less developed regions will increase. ${ }^{[34]}$ Similarly, some scholars have argued that greater global and national equality in the distribution of resources could be the key to successfully reducing some of the environmental risks associated with global population growth (e.g. by reducing the "competitive consumption" of material goods that is more evident in societies with higher income inequalities; see ${ }^{[13,36]}$ ). Hence, population growth and the resultant increase in demand for resources could have an adverse impact on $21^{\text {st }}$ century living standards in a variety of the world's regions.

\subsubsection{Climate Change}

Projections indicate that the greatest levels of population growth will occur in developing regions, such as Central Africa, Central Asia and South America. ${ }^{[37]}$ As observed in the recent economic growth of China, developing countries often produce higher levels of $\mathrm{CO}_{2}$ because fossil fuel consumption is increased and more natural land is cleared (e.g., forestry, which absorbs $\mathrm{CO}_{2}$ ) in order to facilitate economic expansion. ${ }^{[38]}$ Consequently, $\mathrm{CO}_{2}$ emissions in developing regions are likely to increase as efforts are made to meet, at the very least, the food, water, shelter and infrastructural demands that will increase in proportion to the expanding populations. Hence, population growth, 
when coupled with rapid economic growth in developing countries and the $\mathrm{CO}_{2}$ emissions of developed nations, could influence climatic changes in the forthcoming decades. ${ }^{[39]}$

\subsubsection{Man-Made Hazards}

Population growth is likely to lead to an increase in infrastructures that can present risks to humans, non-human species and/or the environment (e.g., noxious waste sites, incinerators, nuclear waste repositories, nuclear power stations, etc.). ${ }^{[24,40]}$ This presents a number of potential issues. First, one might expect an absolute increase in the number of individuals exposed to the risks associated with such facilities in proportion to the number of facilities created. Second, there may be a relative increase in the number of individuals exposed because (a) the opportunity to live away from these locations will decrease as alternative sites are consumed to meet the needs of the increased population, and (b) populations may disproportionately increase close to such facilities due to the near-term economic incentives such as employment and tax benefits (see ${ }^{[41]}$ ). Finally, the urbanization of rural land for such facilities could increase $\mathrm{CO}_{2}$ emissions and damage eco-systems, which may increase the likelihood of climate change, species extinction, and biodiversity loss. ${ }^{[22,43]}$

\subsubsection{Urbanization and Natural Hazards}

Population growth is likely to result in an increased need to utilize additional land for habitation and subsistence, leaving people with less opportunity to avoid living and/or working in locations that are vulnerable to geophysical events such as floods, landslides, earthquakes and tsunamis. ${ }^{[44,45]}$ The catastrophic outcomes of such future geophysical events could, therefore, increase as larger numbers of people are exposed. ${ }^{[46]}$ Furthermore, such vulnerability may be concentrated amongst the poorest people because (a) much of the population growth between now and 2050 is projected to occur in less economically developed regions, ${ }^{[6]}$ and (b) such communities may have limited access to relevant risk management resources (e.g., flood barriers, earthquake resistant buildings, forecasting technology, etc.). Huppert et al. predict that the interaction of population growth and geophysical events will lead to several natural disasters that kill over 10,000 people each year and a "... calamity with a million casualties is just a matter of time." (Huppert et al., 2006, p. 1875). ${ }^{[4]}$ 


\subsubsection{Socio-Political Instability}

History shows that competition for scarce resources can result in conflict and war, both within and between nations, and that countries with large or rapidly expanding populations are more likely to engage in war. ${ }^{[48,49]}$ Whilst it is uncertain whether the frequency of wars will increase as a result of the growing global population, collective evidence indicates that this is likely. ${ }^{[50,51]}$ Furthermore, whilst it is difficult to predict the effect of population growth on migration, past evidence and future projections suggest that a scarcity of resources can drive cross-border and intercontinental migration. ${ }^{[52,53]}$ Hence, competition for resources brought about by population growth could raise the probability of rapid regional changes, geopolitical conflicts, and economic instabilities.

\subsection{Summarizing Population Growth and Risk}

During the past two centuries, academics such as Thomas Malthus, Paul Ehrlich and Stephen Emmott have warned about the adverse consequences of rapid human population growth on all life forms and the natural environment. ${ }^{[14,27,54]}$ Debates regarding the validity of their predictions still continue, with contrarian arguments often focusing on whether such harmful consequences have occurred/will occur or whether the consequences are primarily driven by factors other than population growth (e.g., consumption behaviors, Government inaction, etc.). ${ }^{[22,55,56]}$ Our motivation for highlighting the above empirical evidence and scholarly perspectives (which indicate that the frequency and/or scale of several major adverse events could increase/have increased with global population growth) is not to sway opinions in this ongoing debate but, rather, to highlight why individuals might have reasonable cause to perceive population growth as an independent or contributory risk factor that substantially confounds the fundamental challenges faced by humanity, other life forms, and the environment. Importantly, these perceptions could influence decision making and risk-related behaviors and, therefore, could reflexively shape population growth and the related challenges during this century.

\section{POPULATION GROWTH AND RISK PERCEPTION}


There is much evidence that shows risk perceptions can have a substantial influence on important decisions and behaviors. ${ }^{[17-19]}$ For example, a heightened perceived risk of certain diseases can motivate individuals to adopt protective behaviors such as vaccinations and self-examinations, ${ }^{[57-}$ ${ }^{59]}$ the perceived threat of terrorism can cause individuals to avoid certain locations and modes of transportation, ${ }^{[60,61]}$ and risk perceptions can moderate support for policies concerning issues such as climate change and the location of nuclear facilities. ${ }^{[19,62,63]}$ This literature provides a strong indication that individuals' perceptions of the risks posed by population growth could have a substantial effect on related decisions and behaviors.

Individuals who perceive adverse consequences arising from population growth will, consequently, be confronted with a range of important choices. For example, they may contemplate how they might play a direct role in limiting population growth and this may involve deciding whether they should/can restrain their own family size. ${ }^{[13]}$ Similarly, individuals may consider whether they should pressure policy makers to prioritise actions that may address population growth and which policies they would support/oppose. For instance, whilst the birth-control policies adopted by countries such as China (one-child policy) and Vietnam (two-child-policy) have been widely condemned for infringing human rights and creating socio-psychological and economic hardships, ${ }^{[64,}$ ${ }^{65]}$ some citizens have expressed support (see ${ }^{[66]}$ ) and policy makers may look for public support on alternative strategies with similar objectives (e.g., raising taxes to fund family planning strategies, reducing benefits for larger families, etc.). Furthermore, the continuous changes that are likely to take place as the global population expands will require individuals to adapt. For example, population growth will increase the onus on many individuals to make practical choices about where it is safe to live, whether to migrate, whether to share scarce resources, and so on. Moreover, individuals may also need to make decisions about which changing circumstances (e.g., increased congestion in public spaces, rising fuel prices, etc.) they are willing to tolerate and accommodate, and which they will seek to change. The outcomes from each of these decision dilemmas could have a substantial impact on the extent of population growth or the extent to which population growth increases the likelihood of adverse events. 
The range of decisions that individuals may make in response to the challenges of population growth is extensive and it is likely that individuals will bring a variety of value judgments (e.g., religious beliefs, cultural values, etc.) to bear on these difficult and often emotive decisions. Behavioral sciences research provides an indirect, yet strong indication that the perceived probability and severity of harm of further population growth could also have a significant influence on related decisions and behaviors. Hence, we believe there is considerable value in developing rigorous scientific knowledge concerning the perceived risks of global population growth, how these perceptions might influence decision behaviors, and how these behaviors might shape population growth and the related challenges. We argue that empirical insight into these psychological aspects of population growth would be valuable because they could help to (a) determine the extent to which individuals are aware of and concerned about this issue (b) understand how such concerns may be guided by the individual's (mis)understanding of the issue (c) assess how behaviors are influenced by these concerns and knowledge (d) develop theories of how such behaviors might shape the issue in the future (e) establish whether/how risk communications would be beneficial and, if so, (f) motivate further research that could examine the efficacy of various risk communication approaches. These insights could help individuals better understand and manage the risks, and could inform public policy, which may help reduce the expenditure and suffering that could stem from inaction or poorly developed/executed policies. (see ${ }^{[67,68]}$ ) Hence, in order to identify a number of important questions that could be addressed in future research, we now consider the role that risk perceptions and decision behaviors might play in relation to the challenges of population growth.

\subsection{The Perceived Risks of Population Growth}

Existing research regarding public understanding of population growth has generally taken the form of opinion surveys that have focused on individuals' knowledge of population sizes, growth rates, etc. and has gauged socio-political orientated views regarding national economic impacts and

family planning policies (e.g., ${ }^{[69,70]}$ ). In addition, researchers in the field of social and environmental psychology have found that increased population density in urban areas can lead to psychological 'crowding effects' which can impede some cognitive and affective functions, elicit strong feelings of 
discomfort and hostility, and increase stress and mental health problems, ${ }^{[71-74]}$ (although see ${ }^{[75]}$ ). However, there is an absence of empirical research that provides detailed insights into the perceived risks of population growth and the complexities of how such perceptions are influenced and related to decision behaviors. Consequently, there is uncertainty regarding the extent to which people are concerned about the wide ranging challenges of population growth, the nature of this concern and how motivated, willing and/or capable they are of adopting adaptive or precautionary behaviors. For example, it is unclear if most individuals perceive population growth as having the potential to be the primary driver of substantial adverse ecological, sociological, political and economic changes during the $21^{\text {st }}$ century or, alternatively, as a simple change in the demography of humanity that can be accommodated and which is unlikely to have any substantial impact on global, regional or personal events. Hence, research that provides detailed insights into perceptions of population growth risks would provide an understanding of the extent of individuals' concern about this issue, how such concerns may be guided by knowledge of the related issues, and how these perceptions might influence decision behaviors. Importantly, research could assess the extent to which these perceptions are influenced by a variety of factors (e.g., affect, knowledge, experience, beliefs, socio-demographic characteristics, etc.) that have already been found to have a strong relationship with perceived risk. ${ }^{\text {[76- }}$

${ }^{80]}$ Moreover, as we will discuss below, researchers could examine how these perceptions might vary according to whether individuals construe population growth as a factor affecting themselves (i.e., personal level risks), their local community and environment (i.e., regional level risks), and/or the global population and wider environment (i.e., global level risks).

\subsubsection{Perceptions of Personal Risks}

Risk perceptions and risk behaviors often have a positive correlation (i.e., the greater the perceived risk, the greater the willingness to identify and adopt risk-reduction behaviors), particularly when the individual is personally affected by the risk. ${ }^{[58,81,82]}$ Therefore, in the context of risks at a personal level, a positive correlation may also exist between the extent to which individuals (a) believe global population growth will have an negative impact on their personal safety, living standards and/or freedom of choice and (b) are willing to make choices and adopt behaviors that they 
believe could help address the related risks. From this perspective, one might assume that communicating the personal level risks of population growth to individuals could increase perceived risk and, therefore, motivate risk-reduction behaviors. However, it should be noted that empirical research has shown that heightened risk perceptions can result in a sense of helplessness, which can lead to a reduction in the motivation to adopt preventative behaviors. ${ }^{[83,84]}$ Thus, it might equally be the case that individuals with a heightened perceived risk of the personal threats of population growth may not be motivated to act. This highlights how empirical insights into the relationship between risk perceptions and behaviors in the context of continued population growth would help to determine how risk perceptions might influence precautionary behaviors and how risk-related interventions/communications might assist in motivating and empowering, rather than deterring action.

\subsubsection{Perceptions of Regional Risks}

At the regional level, population growth will lead to an increase in the need for supporting infrastructures (e.g., dwellings, farms, roads, etc.) and, in particular, may lead to infrastructure developments that can be perceived as risky i.e., nuclear power stations, mobile phone masts, 'fracking' sites, etc. ${ }^{[46]}$ Recent history has shown that the imposition of such structures near dwellings and community facilities typically leads affected individuals to become concerned about safety and equity issues. ${ }^{[85,86]}$ While there is already a large body of literature that has examined individuals' reactions to such infrastructure developments $\left(\right.$ see $^{[87]}$ ), this literature has not explored whether such reactions vary when the affected individuals believe that the infrastructures are being imposed as a result of regional population growth. Hence, there is scope for research that assesses whether individuals opposing such facilities would focus on affecting the prohibition or relocation of such developments or would be more inclined to take action to address the issue of regional and/or global population growth. Such research could provide important insights into the wider issue of whether individuals perceive a relationship between population growth and risk-related issues at local/regional levels, and whether such perceptions lead individuals to decide that their risk-reduction behaviors are 
better targeted at the issue of population growth rather than more politically-orientated issues (e.g., infrastructure development).

\subsubsection{Perceptions of Global Risks}

Population growth may increase the likelihood and/or magnitude of global adverse events (e.g., accelerated climate change, resource shortages, etc.). Perceptions of many of these adverse events have already been subject to empirical assessment (e.g., ${ }^{[88,89]}$ ). However, little research has directly examined perceptions of the risks associated with global population growth and how these perceptions might influence individuals' decisions that affect others at a more global level (e.g., supporting foreign aid, making charitable donations, etc.). For example, individuals who are aware of the risks of population growth will be confronted by the notion that other groups of people can be perceived as both victims (e.g., victims of a famine due to global food shortages) and as risks (e.g., the increasing number of people increases the likelihood of food shortages). This 'people as victims, people as risks' paradox could reduce empathy for victims of events related to population growth and, therefore, reduce the extent to which individuals are willing to offer support. Hence, research that explores the influence of the global population size on the perceived value of other individuals/groups would be beneficial because it could help to identify how psychophysics (e.g., the ability to identify changes in a physical stimulus as the magnitude of the stimulus increases ${ }^{[90,91]}$ ) and perceptions of population growth risks might influence pro-social behaviors and whether interventions to promote such behaviors may be beneficial.

\subsection{Summarizing Population Growth and Risk Perception}

Perceptions of the personal, regional and global risks associated with population growth may be interrelated by common themes, such as concerns about environmental degradation or declining living standards due to the increased division of space and finite resources. Yet, it is unclear to what extent individuals' concerns about these themes will mediate their motivation to make precautionary or adaptive decisions. Such decisions are important because they could influence the rate of population growth and the impact that each human life has upon communities and the environment. 
Furthermore, research could explore the influence that these perceptions and decisions might have on the challenges associated with population growth by incorporating these psycho-behavioral factors into extant frameworks that model the pressures which drive humanitarian and environmental problems (e.g., The Drivers-Pressure-State-Exposure-Effect-Actions model). ${ }^{[92]}$ Currently, the dearth of scientific knowledge concerning the perceived risks of population growth hinders our ability to understand how individuals may respond to the issues and shape the related events.

\section{POPULATION GROWTH AND RISK COMMUNICATION}

The magnitude and/or effects of global population growth could be influenced by the ability of individuals to understand how their personal choices (e.g., family size, consumption, policy support, etc.) could influence the course of events. ${ }^{[6,10,93]}$ Given that risk communication can play a central role in informing and influencing decision making processes, ${ }^{[94,95]}$ it could be a vital tool in helping scientists exchange relevant information about population growth with other scientists, policy makers, and the general population. However, risk communication can be a complex process and, when conducted poorly, can lead to decisions that have serious adverse consequences. ${ }^{[95,96]}$ Hence, the use of empirically informed, carefully designed and effectively executed messages concerning population growth could be essential for helping individuals make informed decisions that enable them respond to and manage the related challenges. We now discuss some of the key issues to be considered by risk communicators and we draw upon theoretical perspectives and empirical findings in order to develop directions for future research.

\subsection{Comprehension of Numbers and Scale}

In developing an understanding of population growth and the associated risks it is likely that individuals will need to process and comprehend a variety of quantitative data relating to issues such as population growth rates (e.g., a global annual increase of 73,000,000 people), probabilities (e.g., a 0.05 likelihood that country $\mathrm{X}$ will experience a natural disaster), and more complex numerical data such as conditional probabilities (e.g., a 0.17 increased likelihood that country $\mathrm{Y}$ will experience severe food shortages if the country's population increases by $11,000,000$ before 2030). Extant 
research indicates that effectively communicating such numerical risk-related data could present several challenges. First, findings show that numerical skills can vary significantly between individuals and that lower numerical skills can (a) impede an individual's ability to comprehend messages in which risk-related information is represented quantitatively and (b) influence decision making behaviors. ${ }^{[97-99]}$ Second, evidence indicates that even the most compassionate of individuals can become indifferent to the plight of other individuals that are in large groups, particularly when those individuals are represented statistically. ${ }^{[90,100]}$ Finally, research has questioned whether recipients of numerical probabilities can extract relevant, affective meaning from such data. ${ }^{[101,102]}$ Hence, risk communicators will need to develop means to convey quantitative data that will help individuals of all numerical abilities to (a) understand the issues (b) develop an affective connection with the issues and (c) extract an accurate appreciation of the likelihood and scale of certain adverse outcomes. To help individuals of all numerical abilities understand population growth risks researchers might initially assess the approaches and formats (e.g., frequency formats, icon arrays, etc.) that have been found to be effective in communicating numerical risk information in other domains.

\subsection{The Psychological Distance of Population Growth Risks}

Many of the potential adverse consequences of continued population growth may not increase in frequency and/or impact for several years or decades, and certain consequences may only unfold across extended periods of time or be unique to particular regions of the world. ${ }^{[47,103]}$ The temporal and geographical distances of these potential adverse outcomes may present significant challenges for parties that wish to communicate the risks of population growth. For example, Construal Level Theory posits that, although individuals are capable of thinking about (i) future events (ii) another individual's perspective (iii) remote locations and (iv) a range of alternative outcomes, the farther removed a cognitive target is from the individual's direct experience the 'higher' (i.e., more abstract and less meaningful) the psychological representation of that target. ${ }^{[104,105]}$ Hence, the psychological distance between the individual making the assessment and the potential adverse consequences of population growth could be large because the more severe potential outcomes may be perceived as 
temporally and geographically remote. Evidence from studies concerning risk perceptions of climate change suggests that this large psychological distance could lead to low levels of concern about the risks of population growth and, therefore, reduce the motivation to adopt precautionary behaviors. ${ }^{[89]}$ This highlights a need for studies that identify risk communications that help to reduce the psychological distance of population growth risks. This might be achieved, for example, by presenting individuals with evidence that some consequences of population growth may have already started to manifest (e.g., increased deaths from natural disasters ${ }^{[47]}$ ) and are forecast to increase.

\subsection{The Comprehension and Communication of Complexities}

The circumstances and mechanisms that underlie the challenges of global population growth are complex and obfuscated by uncertainty. This is likely to present several challenges for risk communications concerning population growth. First, the probability of many adverse events (e.g., food shortages, loss of biodiversity, etc.) may increase in line with the accumulation of more humans. Research indicates that individuals often struggle to understand cumulative, incremental increases in risk. ${ }^{[106,107]}$ Consequently, there is a need to identify how best to communicate the cumulative nature of the risks associated with continuous population growth. Second, the interaction of population growth with one or more other factors may lead to synergistic risks (i.e., the risk attributable to the combined risk factors is greater than the sum of the risk attributable to the constituent risk factors). For example, when an expanding population increases its consumption of both fossil fuels and natural land these factors can interact to present a synergistic risk of biodiversity loss. ${ }^{[42]}$ It is, therefore, of some concern that evidence suggests that many individuals may have difficulty understanding specific synergistic risks $\left(\right.$ see $^{[108]}$ ). Finally, the size and effects of global population growth cannot be predicted with accuracy, and these uncertainties may present challenges for risk communicators. For example, studies by Johnson and Slovic indicate that whilst details of uncertainties in risk messages can increase the recipient's estimates of the sources' trustworthiness and honesty, it may also be interpreted as a sign of incompetence. ${ }^{[109,110]}$ Hence, there remains substantial scope for researchers to identify and assess the most efficacious techniques for communicating the complexities of population growth risks. Researchers might start by assessing the extent to which these tasks can be achieved by 
the approaches that have been employed to communicate these and similar complexities in other risk domains ${ }^{[101,111-113]}$.

\subsection{Additional Considerations for Risk Communication Research}

The extant literature highlights additional factors that often play a role in risk communication processes and which could be a focus for future research as public understanding of global population growth matures. For example, both media reports and social processes can serve to attenuate or amplify perceived risk, ${ }^{[14]}$ and factors such as affective imagery and trust in the message source can play a key role in how individuals interpret and utilize risk messages ${ }^{[115,116]}$ It would, therefore, be valuable to understand how these factors may shape individuals' perceptions and behaviors concerning population growth risks. Moreover, cross-national studies could prove valuable in helping to understand how differences in socio-demographic characteristics, societal inequalities and cultural backgrounds may influence interpretations of and responses to such communications. Finally, researchers have highlighted the importance of communications that highlight not only the extent and

nature of risks, but how the message recipient might help address the risks (e.g., ${ }^{[21]}$ ). Hence, future research could assess the extent to which individuals are better able to adopt precautionary or preventative behaviors when they receive messages that provide practical risk management guidance or are delivered in conjunction with relevant materials (e.g., family planning programs, emission reduction initiatives, etc.).

\subsection{Summarizing Population Growth and Risk Communication}

We have outlined some of the key challenges that may be faced by parties that communicate population growth and the associated challenges. We have provided some directions for initial research that could be utilized in the development of risk communications. The ultimate purpose of this research could be to help individuals better understand (a) global population growth and the related risks (b) the relationship between his/her behaviors and those risks and (c) the behaviors (policies) that he/she (policy makers) might adopt to help address each risk. 


\section{PERCEIVED BENEFITS OF POPULATION GROWTH}

We have deliberately based our discussions of the implications of global population growth on the literature that highlights the risks associated with this phenomenon. We have adopted this focus with the intention of motivating research in the behavioral sciences which could play a vital role in helping humanity to manage these risks. However, it should be noted that there is academic literature, supported by a number of popular media reports, that argues that global population growth does not present cause for alarm and, in some instances, has several benefits. ${ }^{[13]}$ For example, both Simon and Kremer indicate that humanity benefits from the technological advancements that arise from the need to solve the challenges (e.g., supplying more food, balancing urbanization with ecological sustainability, etc.) of global population growth. ${ }^{[56,117,118]}$ Moreover, Dobbie argues that growing a nations population through controlled in-migration can help to cope with more immediate issues, such as an aging population or the need for economic development. ${ }^{(119)}$ The existence of this literature provides a clear indication that, just as it is likely that many individuals will perceive risks associated with population growth, others, or even the same individuals, will perceive certain benefits. Hence, we suggest that future research concerning the perceived risks of global population growth could also examine perceptions of the potential benefits and, for example, could assess the extent to which the perceived risks and benefits are positively or negatively correlated (see ${ }^{[120,121]}$ ), or are influenced by certain extrinsic factors (e.g., media, education, etc.). An important outcome of research concerning the perceived benefits of global population growth could be to identify how these perceptions may lead individuals to limit the extent to which they practice related risk management behaviors.

\section{CONCLUSION}

From neo-Malthusian pessimism to Cornucopian optimism, the literature on population growth continues to be underscored by a wide range of conflicting perspectives concerning the consequential impacts of population growth on all life forms and the natural environment. However, there appears to be an emerging consensus in the contemporary literature that behavioural changes will be essential to ensure that humanity successfully navigates the challenges associated with global population growth in the $21^{\text {st }}$ century. Although the scientific study of risk perceptions and 
communications may not provide a panacea for guiding these behavioral changes, in collaboration with the work carried out in other organizations and scientific disciplines, such research does have the potential to make important contributions towards helping individuals, communities and policymakers to make better behavioral decisions in response to the challenges faced. At present, little is known about individuals' risk perceptions of global population growth, how these perceptions might influence their behaviors and, therefore, how these behaviors might affect the quality of life experienced during and beyond the $21^{\text {st }}$ century. We believe it is important that these issues are addressed and we have provided some suggestions for the direction of preliminary research. 


\section{REFERENCES}

1. United States Census Bureau. Historical Estimates of World Population. Available at: http://www.census.gov/population/international/data/worldpop/table_history.php, Accessed on May 1, 2013.

2. United Nations Department of Economic and Social Affairs. World Population Prospects: The 2012 Revision. Available at: http://esa.un.org/unpd/wpp/index.htm, Accessed on September 3, 2013.

3. United States Census Bureau. World Population: 1950 - 2050. Available at: http://www.census.gov/population/international/data/idb/worldpopgraph.php, Accessed on May 1, 2013.

4. Campbell M, Cleland J, Ezeh A, Prata N. Return of the population growth factor. Science, 2007; 315: 1501-1502.

5. Livi-Bacci M. A Concise History of World Population (5th ed.). Malden, MA: John Wiley \& Sons, 2012.

6. Cohen JE. Human Population: The Next Half Century. Science, 2003; 302: 11721175.

7. Omran AR. The Epidemiological Transition: A Theory of the Epidemiology of Population Change. The Milbank Memorial Fund Quarterly, 1971; 49: 509-538.

8. $\quad$ Smith HJ. The shape we're in. Science, 2003; 302: 1171.

9. Zalasiewicz J, Williams M, Steffen W, Crutzen P. The New World of the Anthropocene. Environmental Science \& Technology, 2010; 44: 2228-2231.

10. Satterthwaite D. The implications of population growth and urbanization for climate change. Environment and Urbanization, 2009; 21: 545-567.

11. Kunzig R. Population Seven Billion, National Geographic Magazine, January 2011.

12. Sachs JD. With 7 Billion on Earth, A Huge Task Before Us. Available at: http://edition.cnn.com/2011/10/17/opinion/sachs-global-population/index.html, Accessed on September 3, 2013.

13. Dorling D. Population 10 Billion: The Coming Demographic Crisis and How to Survive it. London, UK: Constable and Robinson Ltd., 2013.

14. Emmott S. 10 Billion. London, UK: Penguin Books Ltd., 2013.

15. 7 Billion Actions. Available at: http://www.7billionactions.org/. Accessed on September 12, 2013. 
16. 7 Billion and Me. Available at: http://www.7billionandme.org/. Accessed on September 12, 2013.

17. Breakwell GM. The Psychology of Risk. Cambridge, UK: Cambridge University Press, 2007.

18. Loewenstein G, Weber EU, Hsee CK, Welch N. Risk as feelings. Psychological Bulletin, 2001; 127: 267-286.

19. Slovic P. Are trivial risks the greatest risks of all? Journal of Risk Research, 1999; 2: 281-288.

20. Cohen J. Population growth and earth's human carrying capacity. Science, 1995; 269: 341-346.

21. Eiser JR, Bostrom A, Burton I, Johnston DM, McClure J, Paton D, van der Plight, White MP. Risk interpretation and action: A conceptual framework for responses to natural hazards. International Journal of Disaster Risk Reduction, 2012; 1: 5-16.

22. Galor O, Weil DN. From Malthusian Stagnation to Modern Growth. The American Economic Review, 1999; 89: 150-154.

23. United Nations Population Fund. Challenges, Opportunities and Action in a World of 7 Billion. Available at: http://www.unfpa.org/public/home/news/pid/7999, Accessed on May 1, 2013.

24. Holdren JP, Ehrlich PR. Human Population and the Global Environment: Population growth, rising per capita material consumption, and disruptive technologies have made civilization a global ecological force. American Scientist, 1974; 62: 282-292.

25. Brown LR. Outgrowing the earth: the food security challenge in an age of falling water tables and rising temperatures. London: Earthscan, 2005.

26. Ehrlich PR, Ehrlich AH. Healing The Planet: Strategies for Resolving the Environmental Crisis. Reading, Massachusetts: Addison-Wesley, 1991.

27. Ehrlich PR, Holdren JP. Impact of Population Growth. Science, 1971; 171: 12121217.

28. York R, Rosa EA, Dietz T. STIRPAT, IPAT and ImPACT: analytic tools for unpacking the driving forces of environmental impacts. Ecological Economics, 2003; 46: 351-365.

29. Olson RL. Sustainability as a Social Vision. Journal of Social Issues, 1995; 51: 15-35.

30. Oskamp S. A sustainable future for humanity? How can psychology help? American Psychologist, 2000; 55: 496-508. 
31. Ehrlich PR, Ehrlich AH. The population bomb revisited. The Electronic Journal of Sustainable Development, 2009; 1: 63-71.

32. Gilland B. World population and food supply: can food production keep pace with population growth in the next half-century? Food Policy, 2002; 27: 47-63.

33. Tomlinson I. Doubling food production to feed the 9 billion: A critical perspective on a key discourse of food security in the UK. Journal of Rural Studies, 2013; 29: 81-90.

34. Borlaug N. Feeding a world of 10 billion people: The miracle ahead. In Vitro Cellular \& Developmental Biology: Plant, 2002; 38: 221-228.

35. Pimentel D, Harman R, Pacenza M, Pecarsky J, Pimentel M. Natural resources and an optimum human population. Population \& Environment, 1994; 15: 347-369.

36. Wilkinson R, Pickett K. The Spirit Level: Why Equality is Better for Everyone. London, UK: Penguin Books Ltd, 2010.

37. Population Reference Bureau. World Population Data Sheet - Interactive Map. Available at: http://www.prb.org/Publications/Datasheets/2012/world-populationdata-sheet/world-map.aspx\#/map/population, Accessed on May 1, 2013.

38. Raupach MR, Marland G, Ciais P, Le Quere C, Canadell JG, Klepper G, Field CB. Global and regional drivers of accelerating CO2 emissions. Proceedings of the National Academy of Sciences, 2007; 104: 10288-10293.

39. Galeotti M, Lanza A. Richer and cleaner? A study on carbon dioxide emissions in developing countries. Energy Policy, 1999; 27: 565-573.

40. Ladd HF. Population growth, density and the costs of providing public services. Urban Studies, 1992; 29: 273-295.

41. Greenberg MR, Metz W, Kaltman M, Wilhelm C. Local planning vs. national policy: Urban growth near nuclear power stations in the United States. Town Planning Review, 1986; 57: 225-237.

42. Travis JMJ. Climate change and habitat destruction: a deadly anthropogenic cocktail. Proceeding of the Royal Society of London: Biological Sciences, 2003; 270: 467-473.

43. McKee JK, Sciulli PW, Fooce CD, Waite TA. Forecasting global biodiversity threats associated with human population growth. Biological Conservation, 2004; 115: 161164.

44. Oh $\mathrm{CH}$, Reuveny R. Climatic natural disasters, political risk, and international trade. Global Environmental Change, 2010; 20: 243-254.

45. Stromberg D. Natural Disasters, Economic Development, and Humanitarian Aid. The Journal of Economic Perspectives, 2007; 21: 199-222. 
46. Coleman L. Frequency of Man-Made Disasters in the 20th Century. Journal of Contingencies and Crisis Management, 2006; 14: 3-11.

47. Huppert HE, Sparks RSJ. Extreme natural hazards: population growth, globalization and environmental change. Philosophical Transactions of the Royal Society A: Mathematical, Physical and Engineering Sciences, 2006; 364: 1875-1888.

48. Le Billon P. The political ecology of war: natural resources and armed conflicts. Political Geography, 2001; 20: 561-584.

49. Ross ML. What Do We Know about Natural Resources and Civil War? Journal of Peace Research, 2004; 41: 337-356.

50. Collier P, Hoeffler A. On economic causes of civil war. Oxford Economic Papers, 1998; 50: 563-573.

51. Goldstone JA. Population and security: How demographic change can lead to violent conflict. Journal of International Affairs, 2002; 56: 3-22.

52. Bilsborrow RE, DeLargy PF. Land Use, Migration, and Natural Resource Deterioration: The Experience of Guatemala and the Sudan. Population and Development Review, 1990; 16:125-147.

53. Postel S. Carrying capacity: Earth's Bottom Line. Challenge, 1994; 37: 4-12.

54. Malthus TR. An Essay on the Principle of Population. London: Johnson, 1993.

55. Fernandez-Villaverde J. Was Malthus right? Economic growth and population dynamics, PIER Working Paper No. 01-046, Available at: http://citeseerx.ist.psu.edu/viewdoc/summary?doi=10.1.1.17.9263, Accessed September 9, 2013.

56. Simon JL. Population growth is not bad for humanity. Paper presented at the National Forum, 1990. Available at: http://www.juliansimon.com/writings/Articles/ZUK1.txt, Accessed on May 13, 2013.

57. Andrade EB. Behavioral Consequences of Affect: Combining Evaluative and Regulatory Mechanisms. Journal of Consumer Research, 2005; 32: 355-362.

58. Brewer NT, Weinstein ND, Cuite CL, Herrington Jr JE. Risk perceptions and their relations to risk behavior. Annals of Behavioral Medicine, 2004; 27: 125-130.

59. Bowen DJ, Alfano CM, McGregor BA, Andersen MR. The relationship between perceived risk, affect, and health behaviors. Cancer Detection and Prevention, 2004; 28: 409-417.

60. Gigerenzer G. Out of the Frying Pan into the Fire: Behavioral Reactions to Terrorist Attacks. Risk Analysis, 2006; 26: 347-351. 
61. Goodwin R, Willson M, Stanley G. Terror threat perception and its consequences in contemporary Britain. British Journal of Psychology, 2005; 96: 389-406.

62. Keller C, Visschers V, Siegrist M. Affective Imagery and Acceptance of Replacing Nuclear Power Plants. Risk Analysis, 2012; 32: 464-477.

63. Leiserowitz A. Climate change risk perception and policy preferences: The role of affect, imagery, and values. Climate Change, 2006; 77: 45-72.

64. Bongaarts J, Greenhalgh S. An Alternative to the One-Child Policy in China. Population and Development Review, 1985; 11: 585-617.

65. Sen A. More than 100 million women are missing. In: Murthy P, Landford-Smith C. (editors) Women's Global Health and Human Rights. Sudbury, MA: Jones and Bartlett Publishers, 1990.

66. Nie Y, Wyman RJ. The One-Child Policy in Shanghai: Acceptance and Internalization. Population and Development Review, 2005; 31: 313-336.

67. Ropeik D, Slovic P. Risk communication: A neglected tool in protecting public health. Risk in perspective, 2003; 11: 1-4.

68. Slovic P, Fischhoff B, Lichtenstein S. Why study risk perception? Risk Analysis, 1982; 2: 283-293.

69. Adamson DM, Belden N, DaVanzo J, Patterson S. How Americans View World Population Issues - A Survey of Public Opinion. RAND Corporation, Santa Monica CA, 1998.

70. Grammich C, DaVanzo J, Stewart K. Changes in American Opinion about Family Planning. Studies in Family Planning, 2004; 35: 197-206.

71. Mackintosh E, West S, Saegert S. Two studies of crowding in urban public spaces. Environment and Behavior, 1975; 7 : 159-184.

72. Evans GW. Behavioral and Physiological Consequences of Crowding in Humans. Journal of Applied Social Psychology, 1979; 9: 27-46.

73. Lederbogen F, Kirsch P, Haddad L, Streit F, Tost H, Schuch P, Wust S, Pruessner JC, Rietschel M, Deuschle M, Meyer-Lindenberg A. City living and urban upbringing affect neural social stress processing in humans. Nature, 2011; 474: 498-501.

74. Bell PA, Greene TC, Fisher JD, Baum A. Environmental Psychology. 5th ed. New Jersey: Lawrence Erlbaum Associates; 2001.

75. Fischer CS, Baldassare M, Ofshe RJ. Crowding Studies and Urban Life: A Critical Review. Journal of the American Institute of Planners. 1975; 41: 406-18. 
76. Barnett JB, Breakwell GM. Risk perception and experience: hazard personality profiles and individual differences. Risk Analysis, 2001; 21: 171-177.

77. Dohle S, Keller C, Siegrist M. Examining the Relationship Between Affect and Implicit Associations: Implications for Risk Perception. Risk Analysis, 2010; 30: 1116-1128.

78. Johnson BB. Advancing understanding of knowledge's role in lay risk perception. Risk: Issues in Health and Safety, 1993; 4: 189-211.

79. Rivers L, Arvai J, Slovic P. Beyond a simple case of black and white: Searching for the White Male Effect in the African-American Community. Risk Analysis, 2010; 30: 65-77.

80. Sjoberg L, Wahlberg A. Risk perception and new age beliefs. Risk Analysis, 2002; 22: 751-764.

81. Eiser JR, Arnold BWA. Out in the midday sun: Risk behaviour and optimistic beliefs among residents and visitors on Tenerife. Psychology and Health, 1999. 14: 529-544.

82. Floyd DL, Prentice-Dunn S, Rogers RW. A meta-analysis of research on protection motivation theory. Journal of Applied Social Psychology, 2000; 30: 407-429.

83. Fischhoff B, Gonzalez RM, Lerner JSSDA. Evolving judgments of terror risks: foresight, hindsight, and emotion. Journal of Experimental Psychology: Applied, 2005; 11: 124-139.

84. Weinstein ND, Lyon JE, Rothman AJ, Cuite CL. Preoccupation and affect as predictors of protective action following natural disaster. British Journal of Health Psychology, 2000; 5: 351-363.

85. Hung H-C, Wang T-W. Determinants and Mapping of Collective Perceptions of Technological Risk: The Case of the Second Nuclear Power Plant in Taiwan. Risk Analysis, 2011; 31: 668-683.

86. Kunreuther H, Fitzgerald K, Aarts TD. Siting Noxious Facilities: A Test of the Facility Siting Credo. Risk Analysis, 1993; 13: 301-318.

87. Greenberg MR. NIMBY, CLAMP, and the Location of New Nuclear-Related Facilities: U.S. National and 11 Site-Specific Surveys. Risk Analysis, 2009; 29: 12421254.

88. Gierlach E, Belsher BE, Beutler LE. Cross-Cultural Differences in Risk Perceptions of Disasters. Risk Analysis, 2010; 30: 1539-1549.

89. Spence A, Poortinga W, Pidgeon N. The Psychological Distance of Climate Change. Risk Analysis, 2011; 32: 957-972. 
90. Fetherstonhaugh D, Slovic P, Johnson S, Friedrich J. Insensitivity to the Value of Human Life: A Study of Psychophysical Numbing. Journal of Risk and Uncertainty, 1997; 14: 283-300.

91. Friedrich J, Barnes P, Chapin K, Dawson I, Garst V, Kerr D. Psychophysical Numbing: When Lives Are Valued Less as the Lives at Risk Increase. Journal of Consumer Psychology. 1999;8(3):277-99.

92. Morris GP, Beck SA, Hanlon P, Robertson R. Getting strategic about the environment and health. Public Health, 2006; 120: 889-903.

93. Barro RJ, Becker GS. Fertility Choice in a Model of Economic Growth. Econometrica, 1989; 57: 481-501.

94. Covello VT. Risk comparisions and risk communication: issues and problems in comparing health and environmental risks. In: Kasperson RES, Stallen PJM (eds). Communicating risks to the public. Dordrecht: Kluwer, 1991.

95. Fischhoff B. Risk perception and communication. In: Detels R, Beaglehole R, Lansang MA, Gulliford M (eds). Oxford Textbook of Public Health. Oxford University Press: Oxford, UK, 2009.

96. Kurz-Milcke E, Gigerenzer G, Martignon L. Transparency in risk communication: Graphical and Analog Tools. Annals of the New York Academy of Sciences, 2008; 1128: $18-28$.

97. Dickert S, Kleber J, Peters E, Slovic P. Numeracy as a precursor to pro-social behaviour: The impact of numeracy and presentation format on the cognitive mechanisms underlying donation decisions. Judgment and Decision Making, 2011; 6: 638-650.

98. Peters E. Numeracy and the Perception and Communication of Risk. Annals of the New York Academy of Sciences, 2008; 1128: 1-7.

99. Peters E, Vastfjall D, Slovic P, Mertz CK, Mazzocco K, Dickert S. Numeracy and decision making. Psychological Science, 2006; 17: 407-413.

100. Slovic P. "If I look at the mass I will never act": Psychic numbing and genocide. Judgement and Decision Making, 2007; 2: 79-95.

101. Lipkus IM. Numerical, verbal, and visual formats of conveying health risks: suggested best practices and future recommendations. Medical Decision Making, 2007; 27: 696-713. 
102. Vahabi M. Verbal versus numerical probabilities: Does format presentation of probabilistic information regarding breast cancer screening affect women's comprehension? Health Education Journal, 2010; 69: 150-163.

103. Steffen W, Grinevald J, Crutzen P, McNeill J. The Anthropocene: conceptual and historical perspectives. Philosophical Transactions of the Royal Society, 2011; 369: 842-867.

104. Trope Y, Liberman N, Wakslak C. Construal Levels and Psychological Distance: Effects on Representation, Prediction, Evaluation, and Behavior. Journal of Consumer Psychology, 2007; 17: 83-95.

105. Trope Y, Liberman N. Construal-level theory of psychological distance. Psychological Review, 2010; 117: 440-463.

106. Doyle J. Judging cumulative risk. Journal of Applied Social Psychology, 1997; 27: 500-524.

107. Slovic P. What does it mean to know a cumulative risk? Adolescents' perceptions of short-term and long-term consequences of smoking. Journal of Behavioral Decision Making, 2000; 13: 259-266.

108. Dawson IGJ, Johnson JEV, Luke MA. Do People Believe Combined Hazards Can Present Synergistic Risks? Risk Analysis, 2012; 32: 801-815.

109. Johnson BB, Slovic P. 'Improving' risk communication and risk managment: legislated solutions or legislated disasters? Risk Analysis, 1994; 14: 905-906.

110. Johnson BB. Risk comparison, conflict, and risk acceptability claims. Risk Analysis, 2004; 24: 131-145.

111. Lipkus IM, Holland JG. The Visual Communication of Risk. Journal of the National Cancer Institute: Monographs, 1999; 25: 149-163.

112. Dawson IGJ, Johnson JEV, Luke MA. Helping Individuals to Understand Synergistic Risks: An Assessment of Message Contents Depicting Mechanistic and Probabilistic Concepts. Risk Analysis. 2013;33(5):851-65.

113. Bonnin-Scaon S, Lafon P, Chasseigne G, Mullet E, Sorum PC. Learning the relationship between smoking, drinking alcohol and the risk of esophageal cancer. Health Education Research, 2002; 17: 415-424.

114. Kasperson RE, Renn O, Slovic P, Brown HS, Emel J, Goble R, Kasperson JX, Ratick R. The social amplification of risk: A conceptual framework. Risk Analysis; 1988: 8: 177-187. 
115. Keller C, Siegrist M, Gutscher H. The role of the affect and availability heuristics in risk communication. Risk Analysis, 2006; 26: 971-979.

116. Peters RG, Covello VT, McCallum DB. The determinants of trust and credibility in environmental risk communication: An empirical study. Risk Analysis, 1997; 17: 4354.

117. Simon JL. Resources, population, environment: An oversupply of false bad news. Science, 1980; 208: 1431-1437.

118. Kremer M. Population growth and technological change: One million BC to 1990. The Quarterly Journal of Economics, 1993; 108: 681-716.

119. Dobbie P. Why we need population growth (and where to put it). Available at: http://www.cbsnews.com/8301-505125_162-31144391/why-we-need-populationgrowth-and-where-to-put-it/, Accessed on May 13, 2013.

120. Finucane ML, Alhakami A, Slovic P, Johnson SM. The affect heuristic in judgments of risks and benefits. Journal of Behavioral Decision Making, 2000; 12: 1-17.

121. Vlek CA, Stallen PJ. Judging risks and benefits in the small and in the large. Organizational Behavior and Human Decision Processes, 1981; 28: 235-271. 


\section{FIGURES}

Figure 1. The recorded, current, and projected size of the human population since $1 \mathrm{AD}$ (historical and current estimates from United States Census Bureau, 2013; projections from United Nations Population Division, 2013).

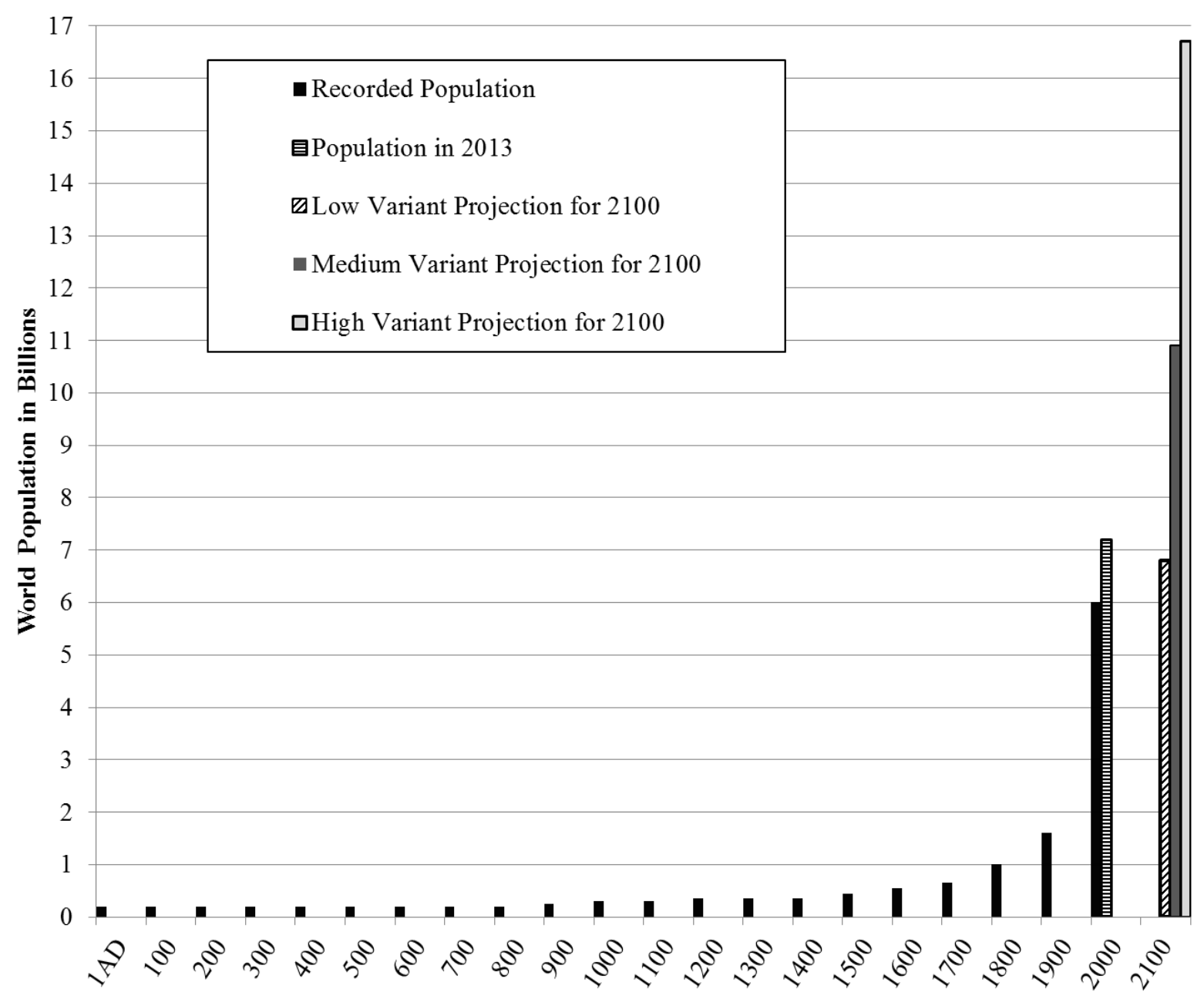

Time in Years 
Figure 2. A model illustrating how the interaction between global human population growth, affluence, and technology can have a multiplicative impact on the environment (Image entitled 'Why is Our Impact Growing?' reprinted with kind permission from Bryan Christie Design, New York. IPAT analysis conducted by Bryan Christie Design in 2011).

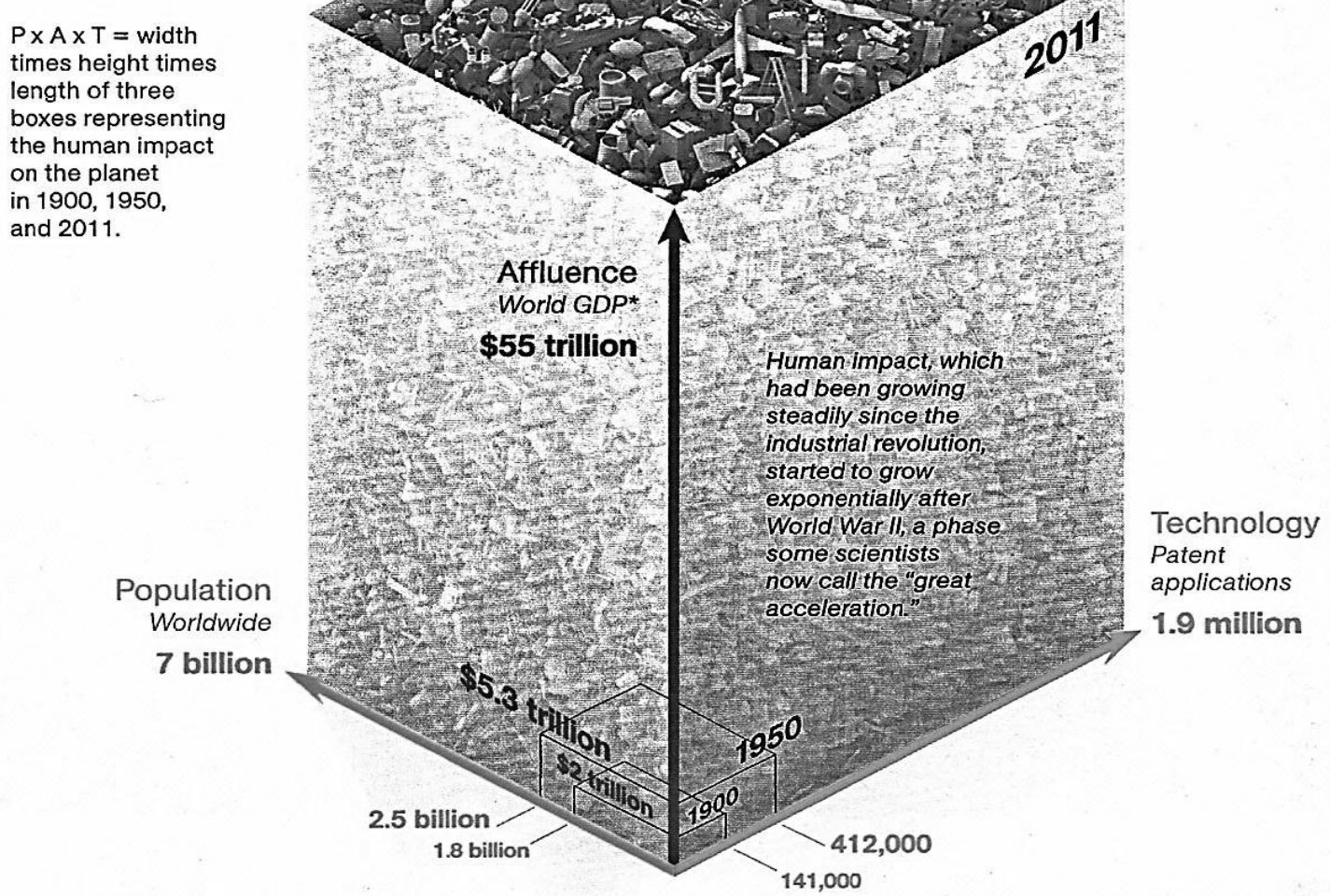

